\title{
Lipopolysaccharide derived from the rumen down-regulates stearoyl-CoA desaturase 1 expression and alters fatty acid composition in the liver of dairy cows fed a high-concentrate diet
}

\author{
Tianle $\mathrm{Xu}^{\dagger}{ }^{\dagger}$ Hui Tao ${ }^{\dagger}$, Guangjun Chang, Kai Zhang, Lei Xu and Xiangzhen Shen ${ }^{*}$
}

\begin{abstract}
Background: Dairy cows are often fed a high-concentrate diet to meet lactating demands, yet long-term concentrate feeding induces subacute ruminal acidosis (SARA) and leads to a decrease in milk fat. Stearoyl-CoA desaturase1 (SCD1) participates in fatty acid biosynthesis in the liver of lactating ruminants. Here, we conducted this study to investigate the impact of lipopolysaccharide derived from the rumen on SCD1 expression and on fatty acid composition in the liver of dairy cows fed a high-concentrate diet. Eight multiparous mid-lactating Holstein cows (455 $\pm 28 \mathrm{~kg}$ ) were randomly assigned into two groups in the experiment and were fed a low-concentrate diet (LC) or high-concentrate diet $(\mathrm{HC})$ for 18 weeks.

Results: The results showed that the total volatile fatty acids and lactic acid accumulated in the rumen, leading to a decreased rumen $\mathrm{pH}$ and elevated lipopolysaccharides (LPSs) in the HC group. The long chain fatty acid profile in the rumen and hepatic vein was remarkably altered in the animals fed the HC diet. The triglyceride (TG), non-esterified fatty acid (NEFA) and total cholesterol $(\mathrm{TCH})$ content in the plasma was significantly decreased, whereas plasma glucose and insulin levels were increased. The expression of SCD1 in the liver was significantly down-regulated in the HC group. In regards to transcriptional regulators, the expression of sterol regulatory element binding transcription factors (SREBF1C, SREBF2) and SREBP cleavage activating protein (SCAP) was down-regulated, while peroxisome proliferator-activated receptor a (PPARa) was up-regulated.

Conclusions: These data indicate that lipopolysaccharide derived from the rumen down-regulates stearoyl-CoA desaturase 1 expression and alters fatty acid composition in the liver of dairy cows fed a high-concentrate diet.
\end{abstract}

Keywords: Lipopolysaccharide, Stearoyl-CoA desaturase 1, Long chain fatty acid, Liver, High concentrate diet, Dairy cows

\section{Background}

Dairy cows are often fed a high-concentrate diet to meet lactating requirements for high milk performance [1]. However, long-term feeding with a high-concentrate diet causes a decline in the rumen $\mathrm{pH}$ if organic acids, such as volatile fatty acids (VFAs) and lactic acid, accumulate in the rumen $[2,3]$, and a chronic digestive disorder known as subacute ruminal acidosis (SARA) may occur. A rumen $\mathrm{pH}$ of less

\footnotetext{
* Correspondence: xzshen@njau.edu.cn

${ }^{\dagger}$ Equal contributors

College of Veterinary Medicine, Nanjing Agricultural University, Nanjing 210095, China
}

than 5.6 for over $3 \mathrm{~h}$ per day is used as a parameter to determine the occurrence of SARA [1]. Decreased rumen $\mathrm{pH}$ results in the release of lipopolysaccharides (LPSs), which originate from the cell-wall component of gram-negative bacteria [4].

Previous studies demonstrated that LPSs stimulate the gene expression of fatty acid synthetase (FAS) and acetyl-CoA carboxylase (ACC) in the liver of mice [5] but depressed stearoyl-CoA desaturase (SCD) expression in bovine hepatocytes [6]. SCD is a rate-limiting enzyme that catalyzes the synthesis of the monounsaturated fatty acids oleate (18:1) and palmitoleate (16:1) and forms triglycerides 
and cholesterol esters [7]. Microarray assays have indicated that the gene expression profile was altered in the liver of SCD knockout mice, and the most obvious pattern was down-regulation of the genes involved in lipogenesis and up-regulation of the genes associated with fatty acid $\beta$ oxidation [8]. It was reported that LPS modulates lipid metabolism by inhibiting the clearance of triacylglycerol in the livers of bovine [9]. Furthermore, in a LPS-induced liver injury model, SCD1 expression was inhibited in the liver of mice, suggesting the potential action of LPS on SCD1 inhibition [10].

The liver is responsible for lipid metabolism in ruminant animals, and SARA is associated with liver abscesses, fatty liver and a whole-body inflammatory response when a high-grain diet is offered [11]. Therefore, the repartition of energy from production to anti-inflammation may exist in the liver and consequently lead to a negative energy balance during long-term high-concentrate supply. Many studies have been carried out on milk fat depression (MFD) in diet-induced SARA [12]. Some studies have focused on the trans fatty acid (i.e., trans-10 C18:1n) pathway [13], while others have paid attention to LPS, which initiates the inflammatory response and influences the fatty acid profile in the rumen and milk [14]. Currently, several studies have been performed to evaluate hepatic lipid metabolism in dairy cows via exogenous LPS infusion [15].However, less information is available in regards to the alterations in hepatic lipid metabolism during longterm diet-induced SARA in dairy cows. Therefore, the present study was conducted to investigate the effects of a high-concentrate diet on the fatty acid composition and SCD1 expression in the liver of dairy cows.

\section{Methods}

\section{Animals, diets and experimental design}

Eight multiparous mid-lactating Holstein cows (455 \pm $28 \mathrm{~kg}$ ) were randomly assigned into two groups. One group was fed with a high-concentrate diet $(\mathrm{HC})$ composed of $40 \%$ forage and $60 \%$ concentrate as a treatment, and the other group was offered a low-concentrate diet (LC) composed of $60 \%$ forage and $40 \%$ concentrate as a control for the 18-week experimental period. The ingredients and nutritional composition of the diets are presented in Table 1. The cows were fitted with a rumen fistula and hepatic catheters two weeks before the experiment and were ensured that they recovered from the surgery. The animals were maintained in individual tie stalls, fed at 0400, 1200, and $2000 \mathrm{~h}$, and had free access to fresh water throughout the experimental time period.

The animal experiment was reviewed and approved by the Institutional Animal Care and Use Committee of Nanjing Agricultural University. The experiment was performed in accordance with the "Guidelines for Experimental Animals" of the Ministry of Science and Technology (Beijing, China).

\section{Table 1 The ingredients in the diets and the nutritional composition}

\begin{tabular}{|c|c|c|}
\hline Ingredients, $\%$ of DM & $\mathrm{LC}^{1}$ & $\mathrm{HC}^{1}$ \\
\hline Corn silage & 30 & 20 \\
\hline Alfalfa & 30 & 20 \\
\hline Maize & 22.78 & 33.6 \\
\hline Wheat bran & 5.15 & 15 \\
\hline Soybean meal & 9.81 & 9 \\
\hline Calcium phosphate dibasic & 0.92 & 0.53 \\
\hline Powder & 0 & 0.52 \\
\hline Salt & 0.35 & 0.35 \\
\hline Premix $^{2}$ & 1 & 1 \\
\hline Total & 100 & 100 \\
\hline \multicolumn{3}{|l|}{ Nutritional Composition ${ }^{3}$} \\
\hline NE MJ/kg & 6.32 & 6.74 \\
\hline CP \% & 16 & 16.2 \\
\hline EE \% & 3.96 & 4.15 \\
\hline NDF \% & 37.71 & 31.92 \\
\hline ADF \% & 22.75 & 17.55 \\
\hline NFC \% & 33.43 & 40.31 \\
\hline Ca \% & 0.9 & 0.8 \\
\hline $\mathrm{P} \%$ & 0.45 & 0.45 \\
\hline
\end{tabular}

${ }^{1} \mathrm{LC}$, low concentrate; $\mathrm{HC}$, high concentrate.

${ }^{2}$ The premix contained VA, 1,900ku/kg; VD, 250ku/kg; VE, 3,000 mg/kg; Niacin, $4,000 \mathrm{mg} / \mathrm{kg} ; \mathrm{Cu}, 1,200 \mathrm{mg} / \mathrm{kg} ; \mathrm{Fe}, 525 \mathrm{mg} / \mathrm{kg} ; \mathrm{Zn}, 13,000 \mathrm{mg} / \mathrm{kg} ; \mathrm{Mn}$ $5,500 \mathrm{mg} / \mathrm{kg} ; \mathrm{l}, 170 \mathrm{mg} / \mathrm{kg} ; \mathrm{Co}, 50 \mathrm{mg} / \mathrm{kg} ; \mathrm{Se}, 27 \mathrm{mg} / \mathrm{kg}$.

${ }^{3}$ The calculated nutritional composition values.

\section{Sample collection and analysis}

The cows were milked at 0500, 1300, and $2100 \mathrm{~h}$, and the milk yield was recorded daily. A 50-mL milk sample was taken to determine the milk fat and milk protein concentrations once a week (MilkoScan ${ }^{\mathrm{TM}}$ FT1, FOSS, Denmark). Samples of the ruminal fluid were taken via the rumen fistula for 3 consecutive days during the $18^{\text {th }}$ week, at 2-h intervals starting at $0400 \mathrm{~h}$ (after the morning feeding) for 12 hours. The samples were filtered through 2 layers of cheesecloth and stored at $-20^{\circ} \mathrm{C}$ for the LPS, VFA, lactic acid and long-chain fatty acid analyses. A blood sample was taken at the same time as the ruminal fluid collection via the hepatic vein catheter and from the jugular vein using 5 -mL vacuum tubes containing sodium heparin as an anticoagulant. The plasma was isolated from the blood samples by centrifugation at $3000 \times \mathrm{g}$ at $4^{\circ} \mathrm{C}$ for $15 \mathrm{~min}$ and was stored at $-20^{\circ} \mathrm{C}$ for the LPS, biochemical parameter, hormones and long chain fatty acid analyses. Liver tissue samples were taken using a punch biopsy with a local anesthesia, and the samples were frozen in liquid nitrogen and then stored at $-70^{\circ} \mathrm{C}$ until the quantitative Real-Time PCR and western blotting analyses. 


\section{LPS and biochemical parameters in the plasma and ruminal fluid}

The LPS concentration in the ruminal fluid and plasma were determined using a chromogenic endpoint assay (CE64406, Chinese Horseshoe Crab Reagent Manufactory Co., Ltd., Xiamen, China) with a minimum detection limit of $0.05 \mathrm{EU} / \mathrm{mL}$. The procedures were performed according to the manufacturer's instructions.

The analyses for the triglyceride, NEFA, total cholesterol and glucose concentrations were performed using commercial kits (Glucose Assay Kit, Rongsheng, Shanghai, China; Nonesterified Free Fatty Acids Assay Kit, Jiancheng, Nanjing, China; Total Cholesterol Reagent Kit, Dongou, Zhejiang, China; Lactic Acid Assay Kit, Jiancheng, Nanjing, China; Triglyceride Reagent Kit, Jiancheng, Nanjing, China) that used an enzymatic colorimetric method read by a microplate reader (Epoch, BioTek, USA). Plasma insulin and glucagon concentration was determined using an Iodine $\left({ }^{125} \mathrm{I}\right)$ Insulin Radioimmunoassay (RIA) Kit and Iodine $\left({ }^{125}\right.$ I) Glucagon Radioimmunoassay (RIA) Kit (Beijing North Institute of Biological Technology, Beijing, China) with Gamma Radioimmunoassay Counter (SN-6105, Hesuo Rihuan Photoelectric Instrument Co., Ltd, Shanghai, China). All of the procedures were performed according to the manufacturer's instructions.

\section{Fatty acid analysis via gas chromatography}

The VFA concentration in the ruminal fluid was determined via gas chromatography (GC) using a FFAP 1233233, 30-m $\times 0.32-\mathrm{mm} \times 0.5-\mu \mathrm{m}$, capillary column (Agilent J\&W GC Columns, Netherlands) on an Agilent 7890A (Agilent Technologies, USA) as described before with some modifications [16]. Crotonate was used as the internal standard.

The total lipids were extracted from the ruminal fluid and plasma using a mixture of polar and non-polar solvents according to Folch et al. at room temperature [17]. The fatty acid methyl esters (FAMEs) were prepared via esterification using sodium methoxide, followed by $14 \%$ borontrifluoride in methanol [18]. Heptadecanoic acid methyl ester served as the internal standard and was added to the samples prior to extraction and methylation. The FAME extracts were used for the gas chromatographic analysis of the total fatty acids. The fatty acid composition was determined using GC with a CP 7489, $100-\mathrm{m} \times 0.25-\mathrm{mm} \times 0.25-\mu \mathrm{m}$, capillary column (Agilent J\&W Advanced Capillary GC Columns, Netherlands) on an Agilent 7890A (Agilent Technologies, USA) with an autosampler, flame ionization detector and split injection. The temperature programming was optimal for the separation of the majority of the C18:1 trans isomers. The initial oven temperature was $150^{\circ} \mathrm{C}$, held for $5 \mathrm{~min}$, then increased to $200^{\circ} \mathrm{C}$ at a rate of $2^{\circ} \mathrm{C} / \mathrm{min}$, held for $10 \mathrm{~min}$, then increased to $220^{\circ} \mathrm{C}$ at $5^{\circ} \mathrm{C} / \mathrm{min}$ and held for $35 \mathrm{~min}$. Helium was used as carrier gas at a flow rate of $1 \mathrm{~mL} / \mathrm{min}$. The injector was set at $260^{\circ} \mathrm{C}$ and the detector at $280^{\circ} \mathrm{C}$. The FAMEs were identified by comparing with the retention times of the standard.

\section{RNA extraction, cDNA synthesis and quantitative real time PCR}

The total RNA was extracted from $50 \mathrm{mg}$ of liver tissue using the RNA iso Plus ${ }^{\mathrm{TM}}$ reagent (Takara Co., Otsu, Japan) via homogenization on ice. The purity and concentration of the RNA were measured using an Eppendorf BioPhotometer Plus (Eppendorf AG, Hamburg, Germany). The first-strand cDNA was synthesized using 250 ng of the total RNA template using the PrimeScript RT Master Mix Perfect Real Time kit (Takara Co., Otsu, Japan). The primers were designed using Premier 6.0 (Premier Biosoft International, USA) and were based on known cattle sequences or those cited in the published literature [19-21] (Table 2), and the primer efficiencies were evaluated prior to use. The qPCR was performed using the SYBR Premix Ex Taq ${ }^{\mathrm{TM}}$ kit (Takara Co., Otsu, Japan) on an ABI 7300 Real-Time PCR System (Applied Biosystems, Foster City, CA, USA) according to the recommendations in the instruction manual. The standard PCR protocol was described in the manual: denaturing at $95^{\circ} \mathrm{C}$ for $15 \mathrm{~s}$, then 40 cycles at $95^{\circ} \mathrm{C}$ for $5 \mathrm{~s}$, and $60^{\circ} \mathrm{C}$ for $31 \mathrm{~s}$. Glyceraldehyde phosphate dehydrogenase (GAPDH) served as the housekeeping gene for normalization, and the $2^{-\Delta \Delta \mathrm{Ct}}$ method was used for the relative quantification.

\section{Western blotting analysis}

The liver samples were homogenized in RIPA lysis buffer (Beyotime, Shanghai, China) using 0.1 M PMSF using a Dounce homogenizer, and the lysate was centrifuged at $15,000 \times \mathrm{g}$ at $4^{\circ} \mathrm{C}$ for $20 \mathrm{~min}$. The protein concentration of the supernatant was determined using bicinchoninic acid (BCA) and bovine serum albumin as standards (Pierce, Rockford, IL, USA). Equal amounts of protein were separated using 10\% SDSpolyacrylamide gel electrophoresis (PAGE) and transferred onto a nitrocellulose membrane (Millipore, Danvers, MA) at $4^{\circ} \mathrm{C}$. After blocking with $10 \%$ nonfat dry milk in tris-buffered saline at $4^{\circ} \mathrm{C}$ overnight, the membrane was washed and incubated with a primary antibody directed against SCD (Polyclonal antibodies raised in goat;sc-23016,Santa Cruz Biotechnology, diluted to 1:200) and HRP affinipure rabbit anti-goat IgG as the secondary antibody (E030130-01, Earth Ox, CA, diluted to 1:10,000). Visualization of the SCD protein was performed using the ECL western blot detection system (ECL plus, Beyotime, Shanghai China). The same membrane was then stripped with striping buffer (AR0153, Boster, Wuhan, China)and was normalized against $\beta$-tubulin (Polyclonal antibodies raised in goat,sc-9935, Santa Cruz Biotechnology, diluted 
Table 2 The gene name, GeneBank accession number, sequence and product size of the primers used for the qRT-PCR

\begin{tabular}{|c|c|c|c|c|}
\hline Gene & Accession $\#^{1}$ & Forward Primer $\left(5^{\prime}-3^{\prime}\right)$ & Reverse Primer $\left(5^{\prime}-3^{\prime}\right)$ & Product Size \\
\hline$\overline{\text { GAPDH }^{\S}}$ & NM_001034034 & GGGTCATCATCTCTGCACCT & GGTCATAAGTCCCTCCACGA & 176 \\
\hline$A C C-a^{\S}$ & NM_174224 & AGCTGAATTTCGCAGCAAT & GGTITTCTCCCCAGGAAAAG & 117 \\
\hline FASN ${ }^{\S}$ & AF285607 & GCATCGCTGGCTACTCCTAC & GTGTAGGCCATCACGAAGGT & 136 \\
\hline $\mathrm{LPL}^{\S}$ & NM_001075120 & GGGTITGAGCAAGGGTACA & GCCACAATGACCTTTCCAGT & 193 \\
\hline FABP1\& & FJ415874.1 & GTTCATCATCACCGCTGGCT & CCACTGCCTTGATCTTCTCCC & 101 \\
\hline PLIN2\& & NM_173980.2 & TTAATGGCCTCATGCTITTGC & CTCAGAGCAGACCCCAATTCA & 100 \\
\hline ACOX1\& & NM_001035289.3 & ACCCAGACTTCCAGCATGAGA & TTCCTCATCTTCTGCACCATGA & 100 \\
\hline CPT1a\& & FJ415874.1 & TCGCGATGGACTTGCTGTATA & CGGTCCAGTTTGCGTCTGTA & 100 \\
\hline$S C D^{\S}$ & NM_173959.4 & TTATTCCGTTATGCCCTTGG & GGTAGTTGTGGAAGCCCTCA & 151 \\
\hline DGAT1\& & FJ415874.1 & CCACTGGGACCTGAGGTGTC & GCATCACCACACACCAATTCA & 101 \\
\hline DGAT2\& & FJ415874.1 & CATGTACACATTCTGCACCGATT & TGACCTCCTGCCACCTTTCT & 100 \\
\hline SREBF1C & FJ415874.1 & CACTCGTCTTCCTCTGTCTC & GAGTGACTGGTTCTCCATAG & 243 \\
\hline SREBF2\& & NM_001205600.1 & AGAGCAAACTCCTGAAGGGC & GGAGGCGACATCAGAAGGAC & 103 \\
\hline SCAP & NM_001101889.1 & CATCAAGCTCTACTCCATCC & CAATGGCAGCGTTGTCCAGCA & 206 \\
\hline LXRa\& & NM_001014861.1 & CCCCATGACCGACTGATGTT & TGTCCTTCATCTGGCTCCACC & 241 \\
\hline PPARa\& & FJ415874.1 & CATAACGCGATTCGTTTTGGA & CGCGGTTTCGGAATCTTCT & 102 \\
\hline
\end{tabular}

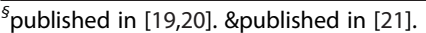

'Entrez Gene, National Center for Biotechnology Information (NCBI).

to $1: 200)$. The procedures for the secondary antibody and visualization were the same as that used for SCD. The ECL signals were recorded using an imaging system (LAS4000, USA) and analyzed using Quantity One (Bio-Rad, USA).

\section{Statistical analysis}

All of the data were expressed as the mean \pm SEM. The statistical data analysis was conducted via unpaired or paired Student's t-tests using IBM SPSS 20.0 Statistics for mac (IBM Inc., New York, USA). A difference was considered to be significant when $p<0.05$.

\section{Results}

Rumen $\mathrm{pH}$, LPS content in the rumen and plasma, and the milk composition

The $\mathrm{pH}$ value in the ruminal fluid is shown in Figure 1. The dynamic $\mathrm{pH}$ curve in the $\mathrm{HC}$ group was lower than that in the LC group during the long-term experiment. It showed that a pH value under 5.6 lasted for $223 \mathrm{mi}$ nutes in the HC group, which indicated that SARA was successfully induced. The $\mathrm{pH}$ value of the $\mathrm{HC}$ group was significantly lower than that of the LC group after the morning feeding for $8 \mathrm{~h}(p<0.05)$.

The LPS concentration in the ruminal fluid of the $\mathrm{HC}$ group was significantly increased, from $47.17 \times 10^{3} \mathrm{EU} /$ $\mathrm{mL}$ to $79.04 \times 10^{3} \mathrm{EU} / \mathrm{mL}$, compared to the LC group $(p<0.01)$. In the peripheral plasma, the LPS level in the $\mathrm{HC}$ group was $0.86 \mathrm{EU} / \mathrm{mL}$, while it was $0.47 \mathrm{EU} / \mathrm{mL}$ in the LC group $(p<0.001)$.
Milk samples were collected from the $1^{\text {st }}$ week to the $18^{\text {th }}$ week to determine the change in the milk composition. The results showed that the milk yield, the percentage of milk fat and the milk fat yield decreased significantly in the HC group compared to the LC group $(p<0.01)$. However, the percentage of milk protein increased remarkably in the $\mathrm{HC}$ group $(p<0.05$; Table 3$)$.

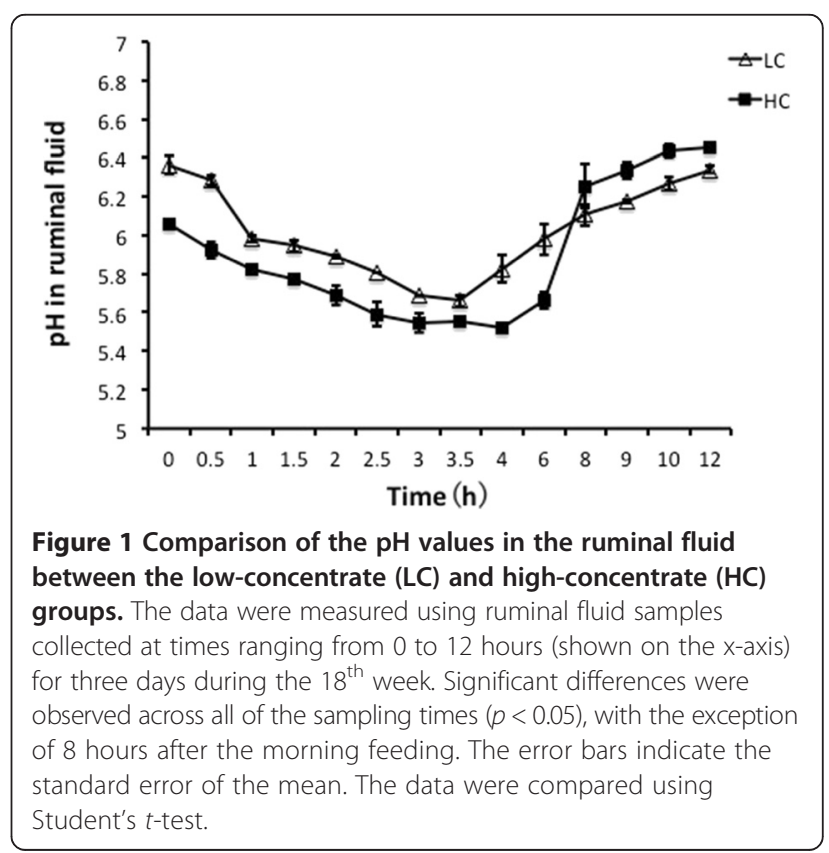


Table 3 The LPS, milk yield and milk composition in the dairy cows fed the low-concentrate (LC) and high-concentrate (HC) diets

\begin{tabular}{|c|c|c|c|c|}
\hline \multirow[t]{2}{*}{ Item } & \multicolumn{2}{|c|}{ Treatment } & \multirow[b]{2}{*}{ SEM $^{1}$} & \multirow[b]{2}{*}{ p-Value ${ }^{2}$} \\
\hline & $\overline{\mathrm{LC}}$ & $\mathrm{HC}$ & & \\
\hline Rumen LPS, EU/mL ${ }^{1}\left(\times 10^{3}\right)$ & 47.17 & $79.04^{b}$ & 7.94 & $<0.01$ \\
\hline Plasma LPS, EU/mL ${ }^{2}$ & 0.47 & $0.86^{a b}$ & 0.08 & $<0.001$ \\
\hline \multicolumn{5}{|l|}{ Milk $^{3}$} \\
\hline Milk yield, kg & 28.05 & $26.92^{b}$ & 0.30 & $<0.01$ \\
\hline Fat, \% & 3.40 & $3.09^{b}$ & 0.03 & $<0.01$ \\
\hline Fat yield, kg/d & 0.95 & $0.84^{b}$ & 0.02 & $<0.01$ \\
\hline Protein, \% & 3.04 & $3.16^{a}$ & 0.03 & $<0.05$ \\
\hline Protein yield, kg/d & 0.85 & 0.85 & 0.02 & 0.98 \\
\hline
\end{tabular}

${ }^{1} \mathrm{SEM}=$ Standard error of the mean between the two groups.

${ }^{2}$ The LPS data were compared using Student's $t$-test. The milk samples were compared using a paired $t$-test.

${ }^{3}$ The milk samples were obtained from the $1^{\text {st }}$ week to the $18^{\text {th }}$ week

${ }^{a b}{ }_{\text {indicates }} p<0.001 ;{ }^{a}$ indicates $p<0.05 ;{ }^{b}$ indicates $p<0.01$.

The VFA profile in the ruminal fluid and the plasma biochemical parameters

The VFA profiles in the ruminal fluid and the biochemical parameters in the peripheral plasma between the LC and $\mathrm{HC}$ groups are presented in Table 4 . When compared to the LC group, the total VFA and lactic acid concentration in the rumen was significantly elevated in the $\mathrm{HC}$ group (105.95 vs. 92.91, $p<0.05$ and 1.55 vs. $0.96 \mathrm{mmol} / \mathrm{L}, p<0.01$, respectively). The molar proportion $(\mathrm{mmol} / \mathrm{mol})$ of propionate was increased in the dairy cows fed the high-concentrate diet (281.83 vs. $247.68, p<0.01$ ), but the other proportional concentrations of the individual VFAs were unchanged. The ratio of propionate to butyrate $(1.18 v s .1 .44, p<0.05)$ was significantly increased, while the ratio of acetate to propionate $(1.84 v s .1 .57, p<0.05)$ was significantly reduced

When compared to the LC group, the triacylglycerol $(p<0.05)$, NEFA $(p<0.01)$ and total cholesterol $(p<0.01)$ concentrations were significantly decreased in the peripheral plasma of the $\mathrm{HC}$ group. However, the glucose and insulin concentration were significantly enhanced $(p<0.01, p<0.05$ respectively) in the plasma of the high-concentrate diet group.

The long-chain fatty acid profiles in the ruminal fluid and the hepatic vein plasma

The LCFA profiles in the ruminal fluid and the hepatic vein plasma are shown in Tables 5 and 6 , respectively. The LCFA concentration in the ruminal fluid and the hepatic vein of the $\mathrm{HC}$ group was lower than that in the LC group, specifically for palmitate C16:0 $(p<0.05)$ and palmitoleate C18:0 $(p<0.05)$. The desaturation index that was determined by calculating the plasma C16:1n9/C16:0 ratio was decreased in the $\mathrm{HC}$ group $(p=0.087)$.
Table 4 The ruminal fluid composition, blood metabolites and hormone level in the dairy cows fed the low-concentrate (LC) diet and high-concentrate (HC) diet

\begin{tabular}{|c|c|c|c|c|}
\hline \multirow[b]{2}{*}{ VFA profile ${ }^{1}$} & \multicolumn{2}{|c|}{ Treatment } & \multirow[b]{2}{*}{ SEM $^{2}$} & \multirow[b]{2}{*}{ p-value ${ }^{3}$} \\
\hline & LC & $\mathrm{HC}$ & & \\
\hline Total VFA(mmol/L) & 92.91 & $107.64^{a}$ & 3.66 & $<0.05$ \\
\hline \multicolumn{5}{|c|}{ Molar proportion, $\mathrm{mmol} / \mathrm{mol}$} \\
\hline Acetate & 454.51 & 440.55 & 3.10 & 0.47 \\
\hline Propionate & 247.68 & $281.83^{b}$ & 2.41 & $<0.01$ \\
\hline Isobutyrate & 25.19 & 24.68 & 0.38 & 0.83 \\
\hline Butyrate & 210.11 & 195.99 & 1.77 & 0.17 \\
\hline Isovalerate & 36.31 & 34.52 & 0.67 & 0.67 \\
\hline Valerate & 21.25 & 19.93 & 0.24 & 0.38 \\
\hline Caproate & 4.95 & $2.49^{b}$ & 0.17 & $<0.01$ \\
\hline Acetate:Propionate & 1.84 & $1.57^{a}$ & 0.02 & $<0.05$ \\
\hline Propionate:Butyrate & 1.18 & $1.44^{b}$ & 0.05 & $<0.01$ \\
\hline Lactic acid & 0.96 & $1.55^{b}$ & 0.20 & $<0.01$ \\
\hline \multicolumn{5}{|c|}{ Plasma biochemical parameter ${ }^{4}$} \\
\hline $\mathrm{TG}(\mathrm{mmol} / \mathrm{L})$ & 0.28 & $0.21^{a}$ & 0.05 & $<0.05$ \\
\hline NEFA (mmol/L) & 1.16 & $0.48^{a b}$ & 0.07 & $<0.001$ \\
\hline TCH (mmol/L) & 2.21 & $1.69^{b}$ & 0.31 & $<0.01$ \\
\hline GLU (mg/dL) & 45.23 & $56.02^{b}$ & 4.54 & $<0.01$ \\
\hline \multicolumn{5}{|l|}{ Hormone level $^{4}$} \\
\hline Insulin ( $\mu \mid \mathrm{U} / \mathrm{mL})$ & 16.95 & $21.57^{a}$ & 1.01 & $<0.05$ \\
\hline Glucagon (pg/mL) & 191.23 & 161.02 & 18.28 & 0.28 \\
\hline Insulin:Glucacon & 0.10 & $0.16^{c}$ & 0.01 & 0.07 \\
\hline
\end{tabular}

${ }^{1}$ The volatile fatty acid and lactic acid concentrations and the mean proportion across the sampling times during the $18^{\text {th }}$ week.

${ }^{2} \mathrm{SEM}=$ Standard error of the mean between the two treatments.

${ }^{3}$ The data were compared using a paired $t$-test.

${ }^{4}$ The mean metabolite concentration in the jugular plasma across the sampling times. TG, triglyceride; NEFA: non-esterified fatty acid; $\mathrm{TCH}$, total cholesterol; GLU, glucose;

$a_{\text {indicates } \mathrm{p}<0.05 ;}{ }^{{ } \text {indicates } \mathrm{p}<0.01 ;}{ }^{a b}{ }_{\text {indicates }}<0.001$.

Additionally, a decrease in the $\Delta^{9}$ monounsaturated oleic acid (C18:1n-9) concentration was observed in the $\mathrm{HC}$ group. Compared with the LC group, the concentration of cis9,trans 11 CLA was similar in the both rumen and plasma. The concentration of trans11 C18:1 was increased in rumen of the HC group $(p=0.067)$, while in the plasma, the trans11 C18:1 content was similar. In regards to $\alpha$-linolenic acid (C18:3n-3), its content in the $\mathrm{HC}$ group was four-fold lower than that of the LC group. However, the content of both $\mathrm{C} 22: 0$ and $\mathrm{C} 22: 1 \mathrm{n}$ 9 was significantly increased $(p<0.05)$ in the HC group. The desaturation index of $\mathrm{C} 18: 1 \mathrm{n}-9 / \mathrm{C} 18: 0$ and cis 9 , trans11 C18:2n/trans11 C18:1n was decreased in the HC group, but no statistical significance was observed. Meanwhile, the presence of longer-chain saturated FAs (C20:0, $p<0.01$; $\mathrm{C} 21: 0, p<0.01$ ), which are produced via ruminal microbial biohydrogenation, was decreased in the $\mathrm{HC}$ group. 
Table $\mathbf{5}$ The fatty acid composition in the ruminal fluid of the dairy cows

\begin{tabular}{|c|c|c|c|c|}
\hline \multirow[t]{2}{*}{$\mu \mathrm{g} / \mathrm{mL}$} & \multicolumn{2}{|c|}{ Treatment } & \multirow[b]{2}{*}{ SEM $^{1}$} & \multirow[b]{2}{*}{ p-Value } \\
\hline & $\mathrm{LC}$ & $\mathrm{HC}$ & & \\
\hline $\mathrm{C} 12: 0$ & 2.67 & 2.05 & 0.27 & 0.28 \\
\hline C13:0 & 3.31 & 2.92 & 0.30 & 0.56 \\
\hline C $14: 0$ & 254.80 & 74.26 & 55.68 & 0.11 \\
\hline C15:0 & 6.25 & 3.47 & 1.05 & 0.21 \\
\hline C16:0 & 147.09 & $96.84^{b}$ & 10.48 & $<0.01$ \\
\hline cis9C16:1 & 3.17 & 2.32 & 0.11 & 0.27 \\
\hline C18:0 & 473.48 & $281.65^{a b}$ & 38.02 & $<0.001$ \\
\hline trans11C18:1n & 4.53 & $11.40^{c}$ & 1.93 & 0.07 \\
\hline C18:1n-9 & 11.36 & 8.93 & 0.65 & 0.05 \\
\hline$C 18: 2 n-6$ & 10.15 & $7.18^{c}$ & 0.89 & 0.09 \\
\hline C20:0 & 6.28 & $4.40^{b}$ & 0.40 & $<0.01$ \\
\hline $6 C 18: 3 n$ & 0.55 & 0.75 & 0.09 & 0.27 \\
\hline C20:1 & 0.52 & $0.35^{b}$ & 0.04 & $<0.01$ \\
\hline C18:3n-3 & 2.65 & 2.04 & 0.27 & 0.30 \\
\hline cis9, trans $11 \mathrm{C} 18: 2 \mathrm{n}$ & 6.61 & 5.27 & 0.45 & 0.15 \\
\hline $\mathrm{C} 21: 0$ & 0.76 & $0.53^{b}$ & 0.05 & $<0.01$ \\
\hline $\mathrm{C} 22: 0$ & 3.53 & 3.10 & 0.17 & 0.23 \\
\hline C23:0 & 1.21 & 1.12 & 0.06 & 0.51 \\
\hline C24:0 & 4.26 & 3.83 & 0.19 & 0.29 \\
\hline$C 24: 1$ & 0.69 & 0.60 & 0.04 & 0.29 \\
\hline C22:6n-3 & 2.21 & 1.83 & 0.13 & 0.17 \\
\hline
\end{tabular}

${ }^{1} \mathrm{SEM}=$ Standard error of the mean between the two treatments.

${ }^{2}$ The data were compared using Student's $t$-test.

${ }^{a}$ indicates $p<0.05 ;{ }^{b}$ indicates $p<0.01 ;{ }^{a b}$ indicates $p<0.001$;

cindicates $0.05<p<0.1$.

mRNA expression of the genes involved in lipid metabolism in the liver

The liver mRNA expression levels of the genes involved in lipid metabolism are presented in Figure 2. The expression levels of the genes associated with fatty acid uptake/transport, lipid formation, fatty acid oxidation and transcriptional regulators of lipogenic enzymes were remarkably altered between the HC and LC groups. There was a decrease in fatty acid binding protein 1 (FABP1) expression $(p=0.09)$ in the HC group compared to the LC group, and LPL was significantly down-regulated in the HC group. Compared with the LC group, the expression of perilipin 2 (PLIN2) $(p<0.05)$ was significantly decreased in the $\mathrm{HC}$ group, and there was 2-fold down regulation of SCD1 expression in the $\mathrm{HC}$ group. The expression of diacylglycerol acyltransferase (DGAT1 and DGAT2) was similar between the two groups, and the expression of ACC $\alpha$ and FAS, which are involved in de novo fatty acid synthesis, showed no significant difference between the HC and LC groups. However, the expression of carnitine palmitoyltransferase $1 \alpha(\mathrm{CPT} 1 \alpha)$
Table 6 The fatty acid composition in the hepatic vein plasma of the dairy cows

\begin{tabular}{|c|c|c|c|c|}
\hline \multirow[t]{2}{*}{$\mu \mathrm{g} / \mathrm{mL}$} & \multicolumn{2}{|c|}{ Treatment } & \multirow[b]{2}{*}{ SEM $^{1}$} & \multirow[b]{2}{*}{ P-Value $^{2}$} \\
\hline & $\overline{\mathrm{LC}}$ & $\mathrm{HC}$ & & \\
\hline$\overline{C 12: 0}$ & 3.57 & 4.04 & 0.20 & 0.26 \\
\hline C13:0 & 5.92 & 6.99 & 0.50 & 0.32 \\
\hline C14:0 & 66.06 & 74.32 & 13.66 & 0.79 \\
\hline C14:1 & 6.47 & $4.39^{c}$ & 0.57 & 0.06 \\
\hline C15:0 & 8.81 & 6.43 & 0.84 & 0.17 \\
\hline C15:1 & 1.39 & 1.25 & 0.09 & 0.49 \\
\hline C16:0 & 92.47 & $71.10^{a}$ & 5.14 & $<0.05$ \\
\hline cis9C $16: 1$ & 5.32 & $2.84^{c}$ & 0.64 & 0.05 \\
\hline C18:0 & 121.33 & $85.5^{a}$ & 8.81 & $<0.05$ \\
\hline trans11C18:1n & 2.92 & 2.93 & 0.09 & 0.96 \\
\hline C18:1n-9 & 62.24 & $40.28^{a}$ & 5.69 & $<0.05$ \\
\hline C18:2n-6 & 277.99 & $71.13^{a}$ & 38.72 & $<0.05$ \\
\hline$C 20: 0$ & 0.89 & $1.02^{a}$ & 0.03 & $<0.05$ \\
\hline$C 20: 1$ & 0.45 & $0.61^{c}$ & 0.05 & 0.10 \\
\hline C18:3n-3 & 25.86 & $6.6^{b}$ & 3.74 & $<0.01$ \\
\hline cis9, trans $11 \mathrm{C} 18: 2 \mathrm{n}$ & 4.56 & 4.57 & 0.07 & 0.98 \\
\hline C21:0 & 1.27 & 1.00 & 0.19 & 0.51 \\
\hline$C 22: 0$ & 0.97 & $1.31^{a}$ & 0.08 & $<0.05$ \\
\hline$C 20: 3 n-6$ & 27.01 & $10.80^{c}$ & 4.41 & 0.07 \\
\hline C22:1n-9 & 1.24 & $1.57^{a}$ & 0.08 & $<0.05$ \\
\hline$C 20: 4 n-6$ & 33.46 & $16.13^{b}$ & 3.84 & $<0.01$ \\
\hline$C 22: 6 n-3$ & 10.57 & $6.20^{a b}$ & 0.83 & $<0.001$ \\
\hline \multicolumn{5}{|l|}{ Desaturation index } \\
\hline cis9 C16:1/C16:0 & 0.05 & $0.04^{c}$ & 0.01 & 0.09 \\
\hline cis9 C18:1/C18:0 & 0.51 & 0.47 & 0.02 & 0.37 \\
\hline cis9,trans11 C18:2/tran11 C18:1 & 1.66 & 1.55 & 0.06 & 0.37 \\
\hline
\end{tabular}

${ }^{1}$ SEM = Standard error of the mean between the two treatments. ${ }^{2}$ The data were compared using Student's $t$-test.

${ }^{a}$ indicates $p<0.05 ;{ }^{b}$ indicates $p<0.01 ;{ }^{a b}$ indicates $p<0.001$; indicates $0.05<p<0.1$.

was up-regulated in the $\mathrm{HC}$ group $(p<0.05)$, whereas the expression of acyl-CoA oxidase 1 (ACOX1) was increased in the HC group $(p=0.10)$.

With respect to transcriptional regulators, the mRNA level of SCAP was down-regulated in the HC group $(p<0.05)$. Meanwhile, both the SREBF1c $(p=0.09)$ and SREBF2 $(p=0.08)$ mRNA expression levels were decreased in the $\mathrm{HC}$ group. However, the mRNA expression of PPAR $\alpha$ was significantly increased in the $\mathrm{HC}$ group $(p<0.05)$. The expression of liver X receptor $\alpha(\mathrm{LXR} \alpha)$ showed no significant difference.

The protein expression of SCD1 in the liver

The protein expression of SCD in the liver is shown in Figure 3. The results demonstrated that the expression 

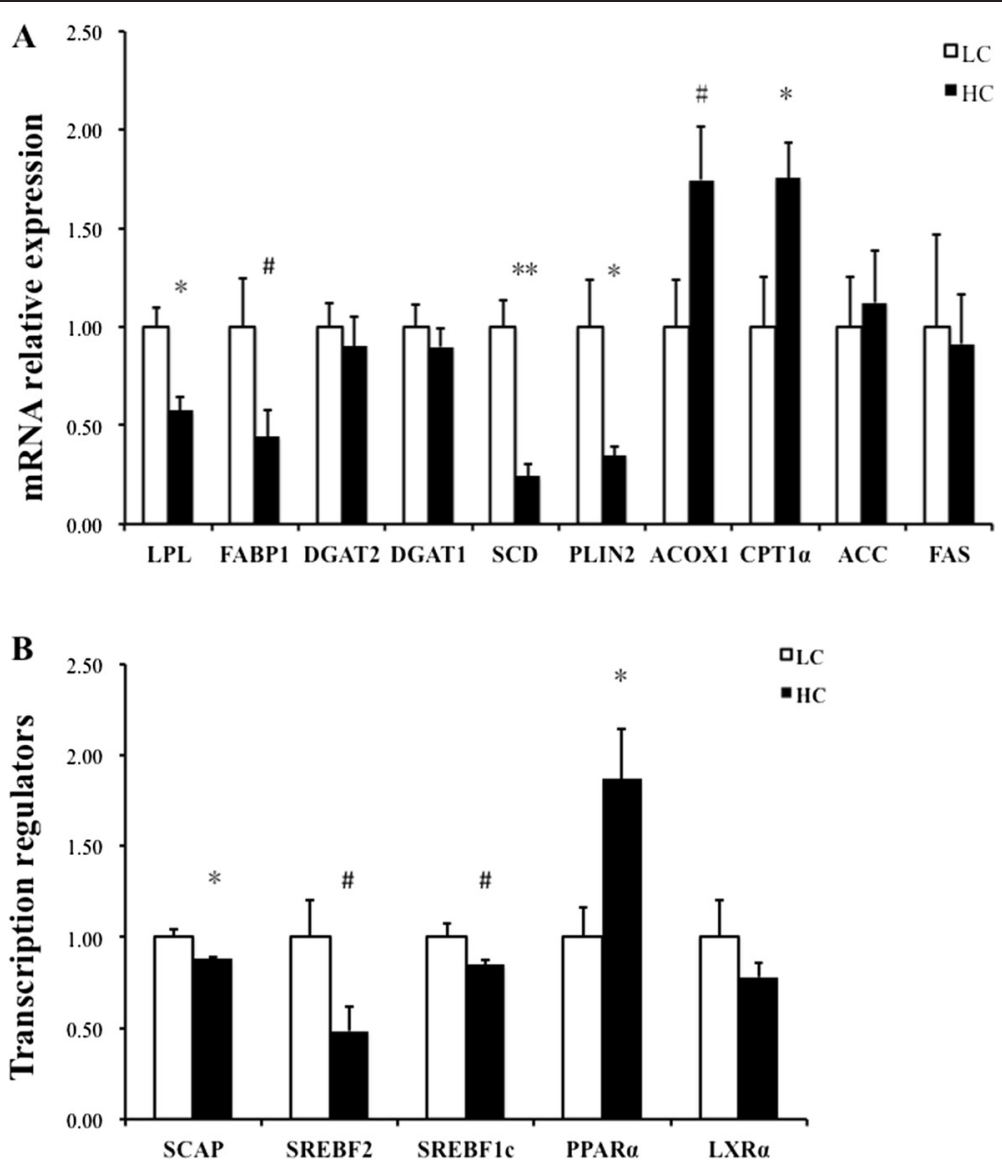

Figure 2 The hepatic gene expression profile analyzed via real-time PCR. Each value was normalized to the expression of GAPDH, and data were compared using Student's t-test between $L C(n=4)$ and HC $(n=4)$. A. The genes involved in desaturation, lipogenesis, fatty acid oxidation, TG synthesis and lipid droplet formation were measured in the liver tissue. The error bars indicate the standard error of the mean. ${ }^{*}$ indicates $p<$ 0.05; ** indicates $p<0.01$; \# indicates significance values between $0.05<p<0.1$. B. The genes involved in transcriptional regulation were measured in the liver tissue. The error bars indicate the standard error of the mean. ${ }^{*}$ indicates $p<0.05$; ${ }^{*}$ indicates $p<0.01$; \# indicates significance values between $0.05<p<0.1$.

of SCD in the liver was significantly down-regulated in the HC group compared to the LC group $(p<0.05)$.

\section{Discussion}

In this study, we showed that an altered fatty acid composition is induced by a $\mathrm{HC}$ diet. The reduced oleate and palmitoleate content may be associated with the down-regulated expression of SCD1 in the liver, which primarily resulted from the release of LPS during longterm $\mathrm{HC}$ feeding. These findings provide insights into the role of endogenous LPS on hepatic SCD1 expression in dairy cows and its relationship with fatty acid composition.

Previous studies have reported that SARA is characterized by declined feed intake, inflammation and depressed milk fat [12]. In our experiment, the duration of a rumen $\mathrm{pH}$ less than 5.6 lasted for $223 \mathrm{~min} /$ day in the cows fed a high-concentrate diet, meanwhile, a decrease in the milk yield $(\mathrm{kg} / \mathrm{d})$, milk fat (\%) and milk fat yield
( $\mathrm{kg} / \mathrm{d})$ was observed in the HC group. Therefore, our results are consistent with other studies.

Our data demonstrated that the total VFA and lactic acid levels in the ruminal fluid were significantly increased in the HC group. The ratio of acetate to propionate was decreased in the $\mathrm{HC}$ group due to an increase in propionate. Early experiments have also presented a low ratio of acetate to propionate in dairy cows fed with easily fermentable carbohydrates [22]. A previous study showed an increased ratio of ruminal propionate to butyrate in repartitioned milk from fat to lactose and protein [23]. In our study, the increased proportion of propionate may be related to glycogenesis $[24,25]$. Because most volatile fatty acids emerge in the portal vein after absorption from the digestive tract [26], alterations in volatile fatty acid concentrations may influence the metabolism in the liver.

When gram-negative bacteria in the rumen are lysed at low $\mathrm{pH}$ values, LPS is released and translocated into 

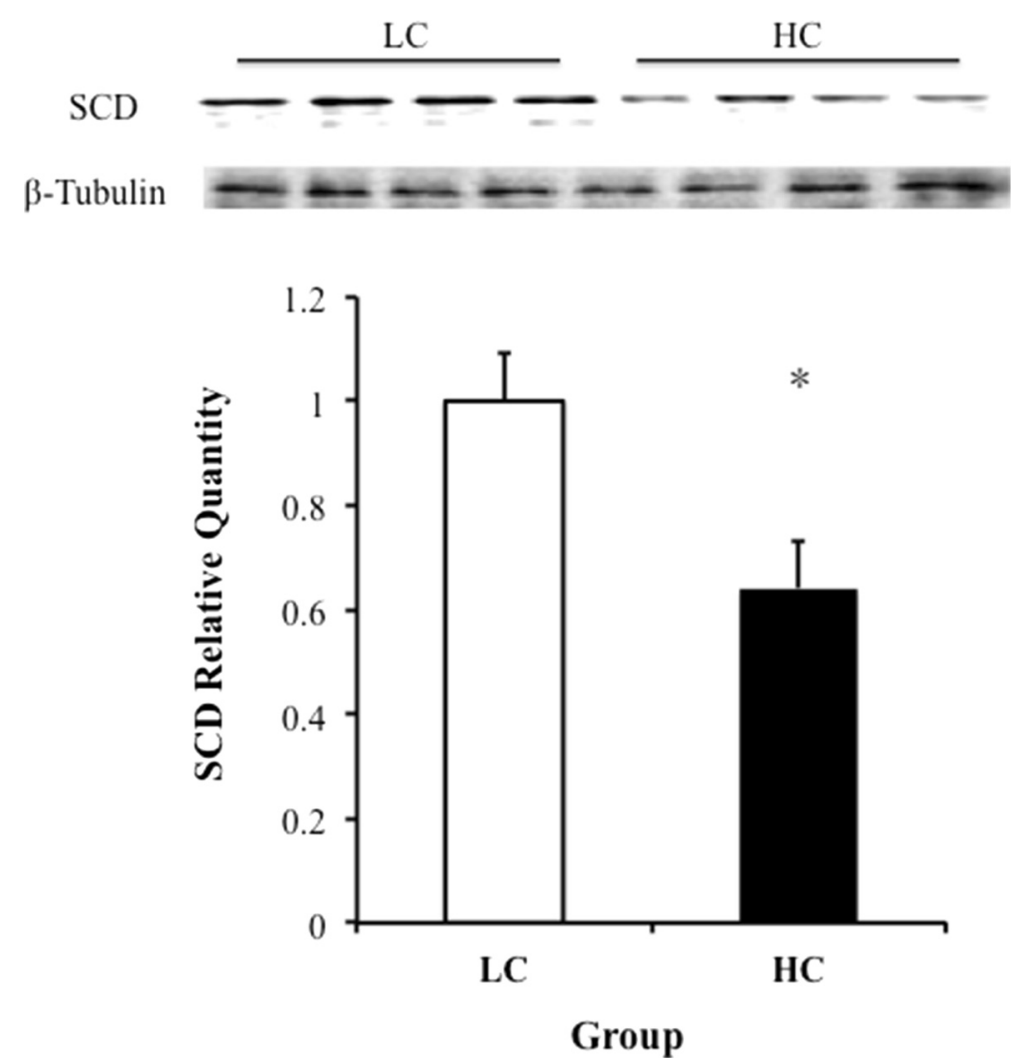

Figure 3 The western blotting analysis of SCD in the liver. The SCD content was assessed via western blotting of the livers of the $L C$ ( $n=4$ ) and $\mathrm{HC}(n=4)$ cows. The protein was quantified via band density measurements of the western blot. The band densities were normalized to the $\beta$-tubulin content within each sample. The data are expressed as the relative amounts of the two groups. * indicates $p<0.05$.The data were compared using Student's t-test.

the bloodstream, initiating an inflammatory response. In our experiment, the high endogenous LPS content may have triggered metabolic disorders in the digestive tract and liver. It has been documented that the liver has a strong ability to clear LPS [27-29]. A recent study showed that the LPS gene expression profile was altered in the liver of lactating goats fed a long-term highconcentrate diet, and the overall metabolism was shifted towards energy supply, in order to meet the higher energy expenditure demands for tissue anti-inflammation [30].

Our results indicated that SARA also influences plasma metabolites. Cholesterol in the plasma is negatively associated with the presence of LPS in the rumen $[31,32]$, which explains our results of lower cholesterol concentrations in the plasma of the $\mathrm{HC}$ group. Among the hormones in peripheral plasma, insulin plays a crucial role in lipid metabolism, particularly in case of feeding cows with a high-concentrate diet. Decreased milk fat yield caused by SARA might have been because of an increased plasma insulin concentration and the ratio of insulin to glucagon $[31,33,34]$, which has shown that high-concentrate diet resulted in greater plasma insulin concentration in our experiment. Due to the higher ruminal propionate and plasma glucose, increased plasma insulin might promote energy expenditure in hepatic through lipolysis and glycolysis, rather than fatty acid synthesis and gluconeogenesis [35], which in turn repressed the expression of lipogenic enzymes, such as SCD1. NEFAs are primarily mobilized from stored TGs in the adipose tissue [36]. In our experiment, the increased propionate and glucose resulted in a decrease in the NEFA concentration in the plasma, which is attributed to their inhibitory effect on adipose tissue lipolysis $[35,37,38]$. A lower TG concentration was observed in the $\mathrm{HC}$ group, which could be explained by the reduced adipose lipolysis and the restriction of biohydrogenation at low rumen pHs [39]. The restricted biohydrogenation led to a decreased saturated FA content, particularly of $\mathrm{C} 16: 0$ and $\mathrm{C} 18: 0$, in the rumen.

The fatty acid profiles in the ruminal fluid and the hepatic vein plasma were altered in this study. Decreased saturated FA concentrations in the ruminal fluid reflects the inhibition of biohydrogenation at lower $\mathrm{pH}$ values in the rumen of cows fed a long-term highconcentrate diet. 
A previous study demonstrated that the conversion of long-chain fatty acids to TGs and phospholipids (PLs) in the livers of dairy cows is dependent on adipose tissue lipolysis [40]. The decrease in the palmitic (C16:0), stearic (C18:0) and oleic (C18:1) content in the liver may be explained by the decreased NEFA levels released from the adipose tissue and the lower production in the rumen. Similarly, a decrease in C18:2n-6 is associated with decreased lipolysis in the adipose tissue [41]. A decrease of both C18:2n-6 and C20:4n-6 in the hepatic vein plasma was observed in the $\mathrm{HC}$ group. It was reported that arachidonic acid (C20:4n-6), which comes from the cell cytoplasm, could be synthesized by $\Delta^{5}$ desaturase from C20:3n-6, and the latter could be desaturated and elongated from C18:2n-6 in the endoplasmic reticulum [42]. In addition, $\alpha$-linoleic acid (C18:3n-3) could be desaturated and elongated to $\mathrm{C} 22: 6 \mathrm{n}-3$, which could explain the decrease in C22:6n-3 in the HC group. Decreased C18:3n-3 may cause an accumulation of TGs [43], due to its function of enhancing the stability of apolipoprotein B:100 [44]. Furthermore, trans11 C18:1n is considered to bethe precursor of trans10 C:18:1n, which is a known inhibitor of milk fat in dairy cows [37]. Therefore, its increased levels in the rumen are associated with milk fat depression.

Fatty acid binding protein 1 (FABP1) is related to fatty acid uptake, transport, and metabolism and the activation of PPAR $\alpha$ via NEFAs [45]. In our study, the downregulated expression of FABP1 was likely observed because of the low NEFA concentrations in the peripheral plasma. As increased levels of trans $11 \mathrm{C} 18: 1 \mathrm{n}$ in the rumen of the $\mathrm{HC}$ group emerged in the portal vein, it may have activated the PPAR $\alpha$ pathway, as was demonstrated in a previous in vitro study [46].

In the liver, the activation of carnitine palmitoyltransferase $1 \alpha(\mathrm{CPT} 1 \alpha)$ and acyl-CoA oxidase 1 (ACOX1) is regulated by PPAR $\alpha$ [8]. In dairy cows, the above enzymes are responsible for regulating the entry of LCFAs into the mitochondria for oxidation $[47,48]$. Because of the increased energy demand to resist inflammation during induced SARA, the gene expression of the above enzymes was increased in the $\mathrm{HC}$ group, which is consistent with the expression of the transcription factor PPAR $\alpha$. Additionally, shorter-chain fatty acyl-CoA, which is produced via peroxisomal fatty acid $\beta$-oxidation, is subsequently channeled to be oxidized completely in the mitochondria [45]. Therefore, the up-regulated expression of CPT $1 \alpha$ suggests that hepatic energy export is necessary during induced SARA.

It was reported that the expression of SREBF1c and FAS, which are involved in lipid synthesis, was down-regulated in SCD1 knockout mice [8]. In our study, the expression of the transcription factor SREBF1c was decreased in the HC group, similar to its activation-dependent ligand SCAP, which could further explain the downregulation of SREBF2. In the liver, SREBF1c regulates the genes involved in fatty acid synthesis, while SREBF2 modulates the genes associated with cholesterol biosynthesis [49]. Therefore, the decreased cholesterol in the plasma could be regulated by SREBF2. SCD is a key lipogenic enzyme that regulates the synthesis of monounsaturated fatty acids, particularly oleate (C18:1) and palmitoleate (C16:1) [50]. The transcription of SCD is co-regulated by SREBF1c and PPAR $\alpha$ [51,52]. The decreased C16:1 and C18:1n-9 content in the hepatic vein plasma indicated the downregulation of SCD in the dairy cows fed a high-concentrate diet. However, the cis9, trans11CLA content was unchanged because the process of trans11C18:1n desaturation to cis9,trans11CLA via SCD exists in most lipogenic and adipogenic tissues, except in the livers of rats and bovine [53,54]. Moreover, it is considered that the $\Delta^{9}$ desaturation index poorly predicts the activity and/or expression of SCD [55]. Similar to SCD, the expression of perilipin 2 (PLIN2), which is involved in the intracellular accumulation of TGs and lipid droplet (LD) formation, was decreased in the HC group [56], which led to the attenuation of LD formation in the liver. Diacylglycerol acyltransferases (DGATs) plays key roles in the synthesis of TGs and very low-density lipoprotein (VLDL) secretion in the liver [57]. In our present study, the similar expression of DGAT1 and DGAT2 between the HC and LC group may be attributed to compensation of the down regulated SCD, which is partly due to a positive correlation between inflammation and fatty liver [58].

A previous study showed that the AMP-activated protein kinase (AMPK) signaling pathway is associated with the inhibition of SCD1 [59]. To some extent, this may contribute to the down regulation of SCD at the mRNA and protein levels. The unchanged mRNA expression of ACC $\alpha$ and FAS may not reflect the phosphorylation status of the enzymes. Therefore, further research is needed to elucidate the underlying mechanism.

\section{Conclusions}

In summary, lipid metabolism in the livers of dairy cows is influenced by long-term high-concentrate diet feeding. Lipopolysaccharide derived from the rumen downregulates stearoyl-CoA desaturase 1 expression and alters fatty acid composition in the liver of dairy cows fed a high-concentrate diet. Our findings may shed light on the regulation of fatty acid metabolism and reprogramming in the livers of dairy cows fed high-concentrate diets.

\section{Abbreviations}

ACOX1: Acyl-CoA oxidase 1; CPT1: Carnitine palmitoyltransferase 1; DGAT: Diacylglycerol acyltransferase; FABP1: Fatty acid binding protein 1; FAME: Fatty acid methyl esters; LCFA: Long chain fatty acid;

LPS: Lipopolysaccharide; LXR: Liver X receptor; PLIN2: Perilipin 2; PPARa: peroxisome proliferator-activated receptor a; SCAP: SREBP cleavage 
activating protein; SCD: Stearoyl-CoA desaturase; SREBF: Sterol regulatory element binding transcription factor; VFA: Volatile fatty acid.

\section{Competing interests}

The authors declare that they have no financial, personal or professional interests that would have influenced the content of the paper or interfered with their objective assessment of the manuscript.

\section{Authors' contributions}

XS and TX: conceived and designed the experiments. TX, HT, GC, KZ and LX: performed the experiments. TX and XS: analyzed the data. TX and XS: drafted the manuscript. All authors read and approved the final manuscript.

\section{Acknowledgements}

This study was supported by the National Basic Research Program of China (2011CB100802), National Natural Science Foundation of China (31172371: 30371040), the Federal Ministry of Food, Agriculture and Consumer Protection of Germany and the Ministry of Agriculture of China (Grant No. 30/2008-2009), and the Priority Academic Program Development of Jinagsu Higher Education Institutions (PAPD).

The authors are grateful to Dr. Dirk Dannenberger and Dr. Karin Nuernberg, from the Leibniz Institute for Farm Animal Biology, Germany, for their valuable advice on fatty acid analysis via gas chromatography (GC).

\section{Received: 10 December 2014 Accepted: 13 February 2015 Published online: 07 March 2015}

\section{References}

1. Gozho GN, Plaizier JC, Krause DO, Kennedy AD, Wittenberg KM. Subacute ruminal acidosis induces ruminal lipopolysaccharide endotoxin release and triggers an inflammatory response. J Dairy Sci. 2005;88:1399-403.

2. Chen Y, Oba M, Guan LL. Variation of bacterial communities and expression of Toll-like receptor genes in the rumen of steers differing in susceptibility to subacute ruminal acidosis. Vet Microbiol. 2012:159(3-4):451-9.

3. Plaizier JC, Krause DO, Gozho GN, McBride BW. Subacute ruminal acidosis in dairy cows: the physiological causes, incidence and consequences. Vet J. 2008;176(1):21-31

4. Emmanuel DG, Dunn SM, Ametaj BN. Feeding high proportions of barley grain stimulates an inflammatory response in dairy cows. J Dairy Sci. 2008;91(2):606-14.

5. Arisqueta L, Nunez-Garcia M, Ogando J, Garcia-Arcos I, Ochoa B, Aspichueta $P$, et al. Involvement of lipid droplets in hepatic responses to lipopolysaccharide treatment in mice. Biochem Biophys Acta. 2013;1831(8):1357-67.

6. Jiang QD, Li HP, Liu FJ, Wang XJ, Guo YJ, Wang LF, et al. Effects of lipopolysaccharide on the stearoyl-coenzyme A desaturase mRNA level in bovine primary hepatic cells. Genet Mol Res. 2014;13(2):2548-54.

7. Ntambi JM. Regulation of stearoyl-CoA desaturase by polyunsaturated fatty acids and cholesterol. J Lipid Res. 1999;40:1549-58.

8. Ntambi JM, Miyazaki M, Stoehr JP, Lan H, Kendziorski CM, Yandell BS, et al. Loss of stearoyl-CoA desaturase-1 function protects mice against adiposity. Proc Natl Acad Sci U S A. 2002;99(17):11482-6.

9. Feingold KR, Staprans I, Memon RA, Moser AH, Shigenaga JK, Doerrler W, et al. Endotoxin rapidly induces changes in lipid metabolism that produce hypertriglyceridemia: low doses stimulate hepatic triglyceride production while high doses inhibit clearance. J Lipid Res. 1992;33:1765-76.

10. Chen C, Shah YM, Morimura K, Krausz KW, Miyazaki M, Richardson TA, et al. Metabolomics reveals that hepatic stearoyl-CoA desaturase 1 downregulation exacerbates inflammation and acute colitis. Cell Metab. 2008;7(2):135-47.

11. Kleen JL, Hooijer GA, Rehage J, Noordhuizen JPTM. Subacute Ruminal Acidosis (SARA): a review. J Vet Med. 2003;50:406-14.

12. Khafipour $E$, Krause DO, Plaizier JC. A grain-based subacute ruminal acidosis challenge causes translocation of lipopolysaccharide and triggers inflammation. J Dairy Sci. 2009;92(3):1060-70.

13. Gaynor PJ, Waldo DR, Capuco AV, Erdman RA, Douglass LW, Teters BB. Milk fat depression, the glucogenic theory, and trans-C18:1 fatty aclds. J Dairy Sci. 1995;78:2008-15
14. Zebeli Q, Ametaj BN. Relationships between rumen lipopolysaccharide and mediators of inflammatory response with milk fat production and efficiency in dairy cows. J Dairy Sci. 2009;92(8):3800-9.

15. Graugnard DE, Moyes KM, Trevisi E, Khan MJ, Keisler D, Drackley JK, et al. Liver lipid content and inflammometabolic indices in peripartal dairy cows are altered in response to prepartal energy intake and postpartal intramammary inflammatory challenge. J Dairy Sci. 2013;96(2):918-35.

16. Hamada T, Omori S, Kameoka K, Horii S, Morimoto H. Direct determination of rumen volatile fatty acids by gas chromatography. J Dairy Sci. 1968;51:228-9.

17. Folch J, Lees M, Sloane Stanley GH. A simple method for the isolation and purification of total lipides from animal tissues. J Biol Chem. 1957;226:497-509.

18. Chouinard PY, Corneau L, Barbano DM, Metzger LE, Bauman DE. Conjugated linoleic acids alter milk fatty acid composition and inhibit milk fat secretion in dairy cows. J Nutr. 1999;129:1579-84.

19. Akbar H, Schmitt E, Ballou MA, Correa MN, Depeters EJ, Loor JJ. Dietary lipid during late-pregnancy and early-lactation to manipulate metabolic and inflammatory gene network expression in dairy cattle liver with a focus on PPARs. Gene Regul Syst Bio. 2013;7:103-23.

20. Bionaz M, Loor JJ. Gene networks driving bovine milk fat synthesis during the lactation cycle. BMC Genomics. 2008:9:366

21. Joseph SJ, Robbins KR, Pavan E, Pratt SL, Duckett SK, Rekaya R. Effect of diet supplementation on the expression of bovine genes associated with fatty acid synthesis and metabolism. Bioinf Biol Insights. 2010;4:19-31.

22. Fairfield AM, Plaizier JC, Duffield TF, Lindinger MI, Bagg R, Dick P, et al. Effects of prepartum administration of a monensin controlled release capsule on rumen $\mathrm{pH}$, feed intake, and milk production of transition dairy cows. J Dairy Sci. 2007:90:937-45.

23. Harri M, Pekka H. Effects of the ratio of ruminal propionate to butyrate on milk yield and blood metabolites in dairy cows. J Dairy Sci. 1996;79:851-61.

24. Blanch M, Calsamiglia S, DiLorenzo N, DiCostanzo A, Muetzel S, Wallace RJ. Physiological changes in rumen fermentation during acidosis induction and its control using a multivalent polyclonal antibody preparation in heifers. J Anim Sci. 2009;87(5):1722-30.

25. Penner GB, Taniguchi M, Guan LL, Beauchemin KA, Oba M. Effect of dietary forage to concentrate ratio on volatile fatty acid absorption and the expression of genes related to volatile fatty acid absorption and metabolism in ruminal tissue. J Dairy Sci. 2009;92(6):2767-81.

26. Bergman EN. Energy contributions of volatile fatty acids from the gastrointestinal tract in various species. Physiol Rev. 1990;70:567-90.

27. Buttenschoen $K$, Radermacher P, Bracht H. Endotoxin elimination in sepsis: physiology and therapeutic application. Langenbecks Arch Surg. 2010;395(6):597-605.

28. Deng M, Scott MJ, Loughran P, Gibson G, Sodhi C, Watkins S, et al. Lipopolysaccharide clearance, bacterial clearance, and systemic inflammatory responses are regulated by cell type-specific functions of TLR4 during sepsis. J Immunol. 2013;190(10):5152-60.

29. Vels L, Rontved CM, Bjerring M, Ingvartsen KL. Cytokine and acute phase protein gene expression in repeated liver biopsies of dairy cows with a lipopolysaccharide-induced mastitis. J Dairy Sci. 2009;92(3):922-34.

30. Dong H, Wang S, Jia Y, Ni Y, Zhang Y, Zhuang S, et al. Long-term effects of subacute ruminal acidosis (SARA) on milk quality and hepatic gene expression in lactating goats fed a high-concentrate diet. Plos One. 2013;8(12):e82850.

31. Zebeli Q, Dunn SM, Ametaj BN. Perturbations of plasma metabolites correlated with the rise of rumen endotoxin in dairy cows fed diets rich in easily degradable carbohydrates. J Dairy Sci. 2011;94(5):2374-82.

32. Bertok L. Bile acids in physico-chemical host defence. Pathophysiol. 2004;11(3):139-45.

33. Piccioli-Cappelli F, Loor JJ, Seal CJ, Minuti A, Trevisi E. Effect of dietary starch level and high rumen-undegradable protein on endocrine-metabolic status, milk yield, and milk composition in dairy cows during early and late lactation. J Dairy Sci. 2014;97(12):7788-803.

34. Waggoner JW, Löest CA, Turner JL, Mathis CP, Hallford DM. Effects of dietary protein and bacterial lipopolysaccharide infusion on nitrogen metabolism and hormonal responses of growing beef steers. J Anim Sci. 2009;87:3656-68.

35. Guo Y, Xu X, Zou Y, Yang Z, Li S, Cao Z. Changes in feed intake, nutrient digestion, plasma metabolites, and oxidative stress parameters in dairy cows with subacute ruminal acidosis and its regulation with pelleted beet pulp. J Anim Sci Biotechnol. 2013;4:31. 
36. Knegsel ATM, Brand H, Graat EAM, Dijkstra J, Jorritsma R, Decuypere E, et al. Dietary energy source in dairy cows in early lactation: metabolites and metabolic hormones. J Dairy Sci. 2007;90:1477-85.

37. Bauman DE, Griinari JM. Regulation and nutritional manipulation of milk fat: low-fat milk syndrome. Livest Sci. 2001;70:15-29.

38. Ametaj B, Bradford B, Bobe G, Nafikov R, Lu Y, Young J, et al. Strong relationships between mediators of the acute phase response and fatty liver in dairy cows. Can J Anim Sci. 2005:85:165-75.

39. Van Nevel CJ, Demeyer DI. Influence of $\mathrm{pH}$ on lipolysis and biohydrogenation of soybean oil by rumen contents in vitro. Reprod Nutr Dev. 1996;36:53-63.

40. Douglas GN, Rehage J, Beaulieu AD, Bahaa AO, Drackley JK. Prepartum nutrition alters fatty acid composition in plasma, adipose tissue, and liver lipids of periparturient dairy cows. J Dairy Sci. 2007;90:2941-59.

41. Rukkwamsuk T, Geelen MJH, Kruip TAM, Wensing T. Interrelation of fatty acid composition in adipose tissue, serum, and liver of dairy cows during the development of fatty liver postpartum. J Dairy Sci. 2000;83:52-9.

42. Ves-Losada A, Maté SM, Brenner RR. Incorporation and distribution of saturated and unsaturated fatty acids into nuclear lipids of hepatic cells. Lipids. 2001;36:273-82.

43. Mashek DG, Bertics SJ, Grummer RR. Metabolic fate of long-chain unsaturated fatty acids and their effects on palmitic acid metabolism and gluconeogenesis in bovine hepatocytes. J Dairy Sci. 2002;85:2283-9.

44. Wu X, Shang A, Jiang H, Ginsberg HN. Demonstration of biphasic effects of docosahexaenoic acid on apolipoprotein B secretion in HepG2 cells. Arterioscl Throm Vas. 1997;17:3347-55.

45. Loor JJ. Genomics of metabolic adaptations in the peripartal cow. Animal. 2010;4(07):1110-39.

46. Pawar A, Jump DB. Unsaturated fatty acid regulation of peroxisome proliferator-activated receptor alpha activity in rat primary hepatocytes. J Biol Chem. 2003;278(38):35931-9.

47. Dann HM, Drackley JK. Carnitine palmitoyltransferase I in liver of periparturient dairy cows: effects of prepartum intake, postpartum induction of ketosis, and periparturient disorders. J Dairy Sci. 2005;88:3851-9.

48. Vluggens A, Andreoletti P, Viswakarma N, Jia Y, Matsumoto K, Kulik W, et al Reversal of mouse acyl-CoA oxidase 1 (ACOX1) null phenotype by human ACOX1b isoform. Lab Invest. 2010;90(5):696-708.

49. Bommer GT, MacDougald OA. Regulation of lipid homeostasis by the bifunctional SREBF2-miR33a locus. Cell Metab. 2011;13(3):241-7.

50. Hofacer R, Magrisso IJ, Jandacek R, Rider T, Tso P, Benoit SC, et al. Omega-3 fatty acid deficiency increases stearoyl-CoA desaturase expression and activity indices in rat liver: positive association with non-fasting plasma triglyceride levels. Prostag Leukotr Ess. 2012;86(1-2):71-7.

51. Biddinger SB, Almind K, Miyazaki M, Kokkotou E, Ntambi JM, Kahn CR. Effects of diet and genetic background on sterol regulatory element-binding protein-1c, stearoyl-CoA desaturase 1, and the development of the metabolic syndrome. Diabetes. 2004;54:1314-23.

52. Miyazaki M, Dobrzyn A, Sampath H, Lee SH, Man WC, Chu K, et al. Reduced adiposity and liver steatosis by stearoyl-CoA desaturase deficiency are independent of peroxisome proliferator-activated receptor-alpha. J Biol Chem. 2004;279(33):35017-24

53. Shen X, Nuernberg K, Nuernberg G, Zhao R, Scollan N, Ender K, et al. Vaccenic acid and cis-9, trans-11 CLA in the rumen and different tissues of pasture- and concentrate-fed beef cattle. Lipids. 2007:42(12):1093-103

54. Gruffat D, Torre ADL, Chardigny J-M, Durand D, Loreau O, Bauchart D. Vaccenic acid metabolism in the liver of rat and bovine. Lipids. 2005;40:295-301.

55. Invernizzi G, Thering BJ, McGuire MA, Savoini G, Loor JJ. Sustained upregulation of stearoyl-CoA desaturase in bovine mammary tissue with contrasting changes in milk fat synthesis and lipogenic gene networks caused by lipid supplements. Funct Integr Genomics. 2010;10(4):561-75.

56. Chang $\mathrm{BH}$, Chan L. Regulation of triglyceride metabolism. III emerging role of lipid droplet protein ADFP in health and disease. Am J Physiol Gastrointest Liver Physiol. 2007;292(6):G1465-8.

57. Yamazaki T, Sasaki E, Kakinuma C, Yano T, Miura S, Ezaki O. Increased very low density lipoprotein secretion and gonadal fat mass in mice overexpressing liver DGAT1. J Biol Chem. 2005;280(22):21506-14.
58. Bradford BJ, Mamedova LK, Minton JE, Drouillard JS, Johnson BJ. Daily injection of tumor necrosis factor-\{alpha\} increases hepatic triglycerides and alters transcript abundance of metabolic genes in lactating dairy cattle. J Nutr. 2009;139(8):1451-6.

59. Dobrzyn P, Dobrzyn A, Miyazaki M, Cohen P, Asilmaz E, Hardie DG, et al. Stearoyl-CoA desaturase 1 deficiency increases fatty acid oxidation by activating AMP-activated protein kinase in liver. Natl Acad Sci USA. 2004;101(17):6409-14.

\section{Submit your next manuscript to BioMed Central and take full advantage of:}

- Convenient online submission

- Thorough peer review

- No space constraints or color figure charges

- Immediate publication on acceptance

- Inclusion in PubMed, CAS, Scopus and Google Scholar

- Research which is freely available for redistribution 